\title{
XPS investigation of adsorption protective layers based on industrial inhibited oil
}

\author{
I.N. Shabanova, ${ }^{1 *}$ S.M. Reshetnikov, ${ }^{1,2}$ E.A. Naimushina ${ }^{1,3}$ and \\ N.S. Terebova ${ }^{1}$ \\ ${ }^{1}$ Institution of Science "Udmurt Federal Research Centre of the Ural Branch of the \\ Russian Academy of Sciences”, 34, Tatyana Baramzina St., Izhevsk, 426067, Russian \\ Federation \\ ${ }^{2}$ Udmurt State University, 1, Universitetskaya St., bld. 1, off. 240, Izhevsk, 426034, Russian \\ Federation \\ ${ }^{3}$ M.T. Kalashnikov Izhevsk State Technical University, 7, Studencheskaya St., Izhevsk, \\ 426069, Russian Federation \\ E-mail:xps@udman.ru
}

\begin{abstract}
The X-ray photoelectron spectra of steel surface covered with a protective layer of industrial oil with different content of nitrated oil as an inhibiting additive have been studied in the temperature range from room temperature to $200^{\circ} \mathrm{C}$. It has been shown that the formation of a strong protective layer takes place due to the formation of donor-acceptor bonds between iron and nitrogen atoms. Upon the action of temperature on a sample in the spectrometer chamber (in vacuum) with simultaneous recording the X-ray photoelectron spectra, no changes in the character of the bond of the protective layer and substrate have been revealed. Corrosion tests show that after heating of the samples in a muffle furnace, strengthening of the protective layer and improvement of its protective properties take place. The corrosion rate of the layers containing nitrated oil decreases by a factor of 1.5-2.5 in comparison with that of the layers containing the standard conservation lubricant K-17.
\end{abstract}

Keywords: X-Ray photoelectron (XPS) spectra, interatomic interaction, protective layer, nitrated oil.

Received: June 29, 2020. Published: July 14, 2020

doi: $\underline{10.17675 / 2305-6894-2020-9-3-6}$

\section{Introduction}

The metal protection against atmospheric corrosion still remains the subject of numerous investigations since various kinds of corrosion damages lead to sizable losses of metal reserves and increase of ecological tension [1-3]. Among the existing methods of the protection of metal items against atmospheric corrosion the simplest from technological point of view and most effective is the use of compositions based on mineral oils with the addition of corrosion inhibitors [4-7]. Current range of such protective materials is rather wide. The most effective are additives obtained by oil nitration. Inhibiting additives and 
compositions based on nitrated mineral oils form an adsorption film on the metal surface preventing the penetration of aggressive substances and moist.

Such additives can be obtained by oxidative nitration of mineral oils (or oil products in general) by the direct action of nitric acid on hydrocarbons. In this case different products are formed containing chemically adsorbed active groups:

Nitro compounds with the general formula $\mathrm{R}-\mathrm{CH}_{2}-\mathrm{NO}_{2}$ (here and further, $\mathrm{R}$ is hydrocarbon-based groups including aromatic groups);

Products of hydrocarbons oxidation:<smiles>[R]CC(=O)O</smiles>

The depth of transformation reached is $40-50 \%$. Half of the reacted hydrocarbons are nitro compounds and another half is oxy- and hydroxy-compounds.

First the reaction mixture is separated from the unreacted nitric acid and washed for removing water-soluble products and unreacted nitric acid, and then it is neutralized with the aqueous solution of sodium hydroxide. The nitro-, oxy-nitro- and hydroxy-compounds transform into corresponding sodium salts. Thus, surface-active substances dissolved in the initial (unreacted) oil are synthesized. The mixture obtained is separated from water-soluble products and further it is called corrosion inhibitor or nitrated oil which is added into the oils used for items protection.

It should be noted that an increase in the effectiveness of anticorrosion additives can be associated with the chemisorption of added surfactants, up to the formation of chemical, most often covalent bonds between the metal surface and heteroatomic additives [8-12].

The objective of the present work is the XPS study of the interatomic interaction in the protection coatings based on the industrial oil I-20 on Steel 3 surface and the determination of the corrosion rate of a coating without additives and coating with the addition of oil K-17 and nitrated oil, the adsorption layer of which is formed in the temperature range of room temperature $-250^{\circ} \mathrm{C}$.

\section{Experimental}

The XPS studies were carried out using an X-ray electron magnetic spectrometer with resolution of $10^{-4}$, luminosity of $0.085 \%$ at the excitation with $\mathrm{Al} \mathrm{K \alpha}$ line $1486.5 \mathrm{eV}[13,14]$. The use of X-ray electron magnetic spectrometers is advantageous because of the constructive separation of a magnetic energy analyzer from a vacuum chamber. This allows heating samples in the spectrometer chamber with simultaneous spectra registration.

The following objects were studied:

1. Steel 3 substrate;

2. Thin layer of mineral oil I-20 applied on the substrate surface; 
3. Thin layer of oil $\mathrm{I}-20+10 \mathrm{~g} / \mathrm{L}$ of corrosion-protective grease $\mathrm{K}-17$ applied on the substrate surface (grease K-17, GOST 10877-76);

4. Thin layer of oil I- $20+20 \mathrm{~g} / \mathrm{L}$ of grease K-17 applied on the substrate surface;

5. Thin layer of oil I-20+10 g/L of nitrated oil applied on the substrate surface;

6. Thin layer of oil I-20+20 g/L of nitrated oil applied on the substrate surface;

7. For identifying the chemical bond $\mathrm{Fe}-\mathrm{N}$, thin layers of nitrobenzoic acid were studied.

\section{Results and Discussion}

The peculiar features of the chemical structure of the surface protective layers on Steel 3 obtained at the adsorption of conservation compositions based on mineral oils have been studied. The XPS spectra C1s, O1s, Fe2p and N1s of the core levels of the studied samples have been obtained.

The XPS study of the surface of a substrate made from Steel 3 on which the studied oil is applied shows that at room temperature there are two components $\mathrm{Fe}_{\text {pure }}(707 \mathrm{eV})$ and $\mathrm{Fe}-$ $\mathrm{O}(710 \mathrm{eV})$ in the Fe2p spectrum (Figure 1a, spectrum 1). In the O1s-spectrum there are two components due to the bond of $\mathrm{Fe}$ and $\mathrm{O}(530 \mathrm{eV})$ and $\mathrm{O}_{\text {ads. }}(532.3 \mathrm{eV})-$ oxygen adsorbed on the sample surface (Figure 1b, spectrum 1). When the sample surface is cleaned from impurities by heating in the range of $50^{\circ} \mathrm{C}-500^{\circ} \mathrm{C}$, oxides are removed from the surface of Armco iron, and the only component $\mathrm{Fe}_{\text {pure }}(707 \mathrm{eV}$ ) remains in the $\mathrm{Fe} 2 \mathrm{p}$ spectrum (Figure 1a, spectrum 2).

The position of the maximum of the C1s-spectrum (Figure 1c, spectra 1,2) does not change and corresponds to the bond $\mathrm{C}-\mathrm{H}(285 \mathrm{eV})$ in hydrocarbons; however, at heating the spectrum contrast decreases by half. The formation of the $\mathrm{Fe}-\mathrm{C}$ bond is not revealed.

In the Fe2p spectrum of the thin layer of oil I-20 on Steel 3, which has not been nitrated, in the absence of heating there are two components $\mathrm{Fe}_{\text {pure }}(707 \mathrm{eV})$ and a maximum $\mathrm{Fe}-\mathrm{O}$ (709 eV) coinciding with $\mathrm{Fe}_{2} \mathrm{O}_{3}$ in position (Figure 1a, spectrum 3). At heating to $500^{\circ} \mathrm{C}$ the small maximum $\mathrm{Fe}-\mathrm{O}$ remains (Figure 1a, spectrum 4). In the $\mathrm{O} 1 \mathrm{~s}$ spectrum (Figure $1 \mathrm{~b}$, spectra 3,4$)$ at temperatures lower than $500^{\circ} \mathrm{C}$ there is also a small $\mathrm{O}-\mathrm{Fe}$ component $(530 \mathrm{eV})$.

In the Fe2p spectrum of the nitrated oil on Steel 3 surface without heating, in addition to the maximum in the region of pure iron there are two maxima in the region of the $\mathrm{Fe}-\mathrm{O}$ bond $\left(709-711 \mathrm{eV}\right.$ ) (Figure 1a, spectrum 5). At heating to $\sim 100-200^{\circ} \mathrm{C}$, in the $\mathrm{Fe} 2 \mathrm{p}$ spectrum the maximum characteristic of the pure iron region increases. At temperatures above $200^{\circ} \mathrm{C}$ the position of the main maximum in the $\mathrm{Fe} 2 \mathrm{p}$ spectrum corresponds to pure iron or the covalent bond (donor-acceptor bond) of iron and nitrogen $\mathrm{Fe}-\mathrm{N}(707.0 \mathrm{eV})$ (Figure 1a, spectrum 6)

In the spectrum O1s (Figure 1b, spectrum 5), there are two maxima characteristic of iron oxide and adsorbed oxygen. 


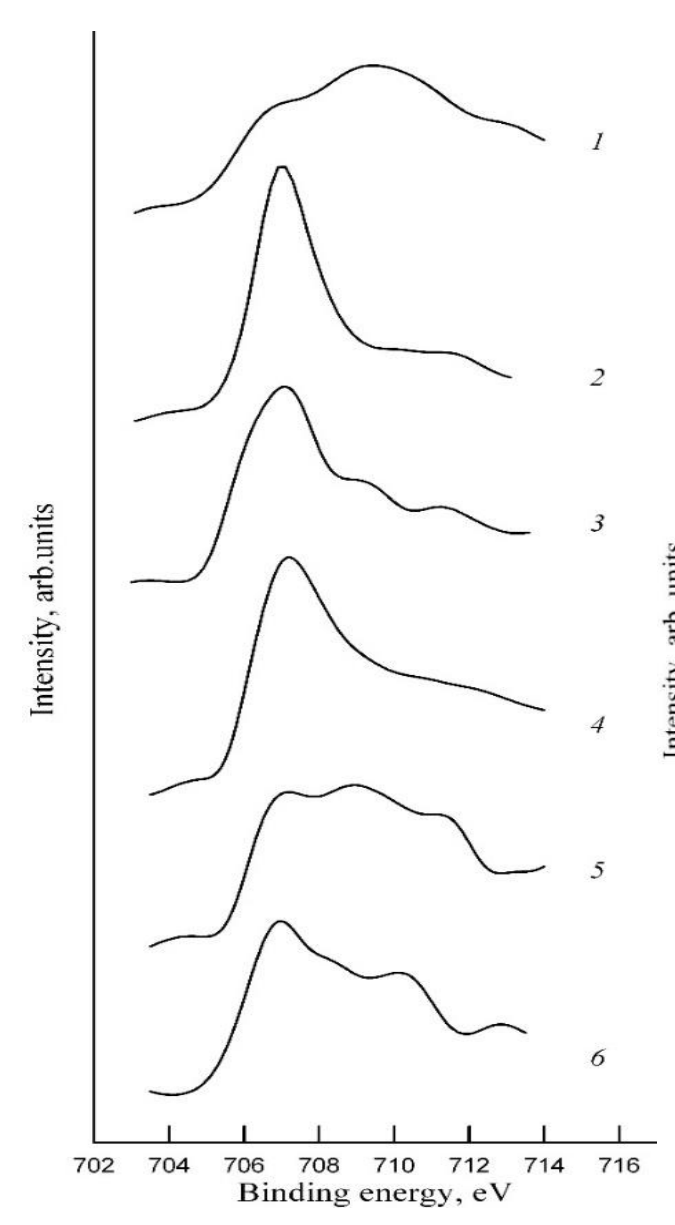

a

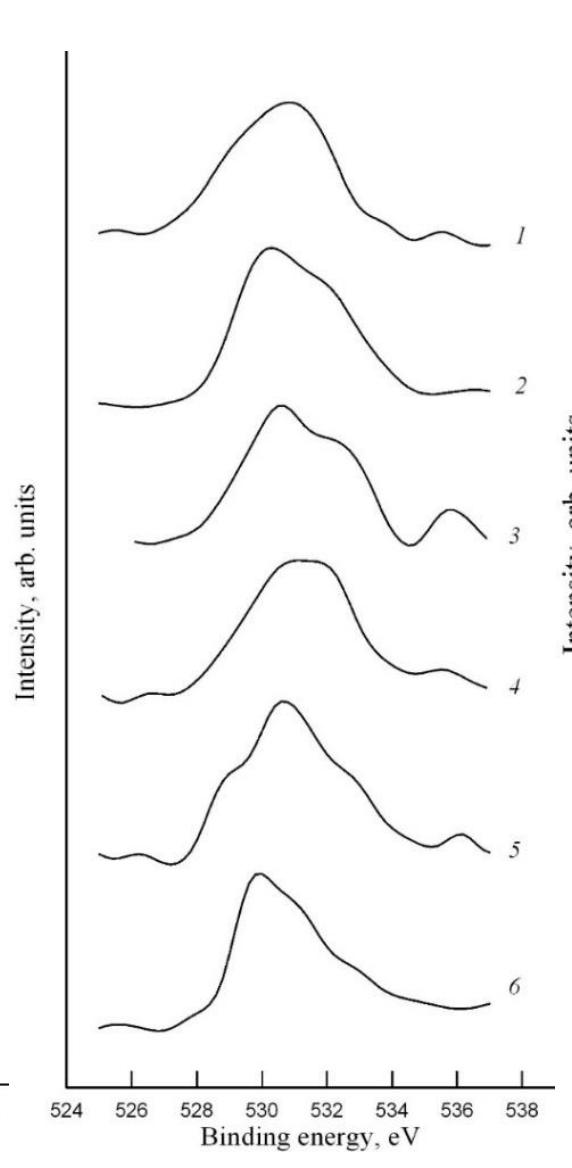

b

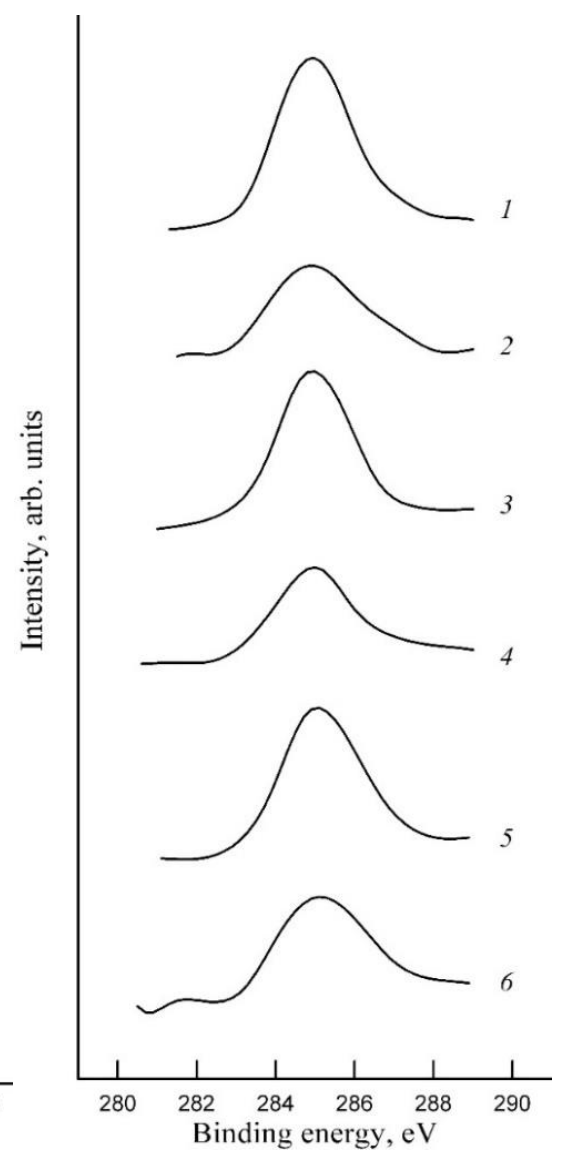

C

Figure 1. XPS Fe2p (a), O1s (b), and C1s (c) spectra of: (1) Steel 3 surface without heating; (2) Steel 3 surface at heating; (3) the mineral oil on Steel 3 surface without heating; (4) the mineral oil on Steel 3 surface with heating; (5) the nitrated oil on Steel 3 surface without heating; (6) the nitrated oil on Steel 3 surface at heating.

Without heating, in addition to the main maximum with the energy of $401 \mathrm{eV}$ characteristic of the bond $\mathrm{N}-\mathrm{O}(\mathrm{N}-\mathrm{Fe}-\mathrm{O})$ in the $\mathrm{N} 1 \mathrm{~s}$-spectrum, on the side of small binding energies there is a small maximum corresponding to the bond $\mathrm{N}-\mathrm{Fe}$ (Figure 2, spectrum 1). At heating above $200^{\circ} \mathrm{C}$ an intensive maximum $\mathrm{N}-\mathrm{Fe}$ with the binding energy of $399 \mathrm{eV}$ (Figure 2, spectrum 2) is revealed in addition to the bond $\mathrm{N}-\mathrm{Fe}-\mathrm{O}$. Above $300^{\circ} \mathrm{C}$, the content of nitrogen decreases, but the bond $\mathrm{N}-\mathrm{Fe}$ remains even at heating to $500^{\circ} \mathrm{C}$.

Thus, the results of the investigation of the nitrated oil sample and their comparison with the results obtained for the reference sample show that:

1) in the protective layer a donor-acceptor bond of iron and nitrogen $\mathrm{Fe}-\mathrm{N}$ is formed;

2) at heating above $200^{\circ} \mathrm{C}$ the content of nitrogen, which is not strongly bound to the substrate, decreases; however the covalent (donor-acceptor) $\mathrm{Fe}-\mathrm{N}$ bond is preserved up to $500^{\circ} \mathrm{C}$. 


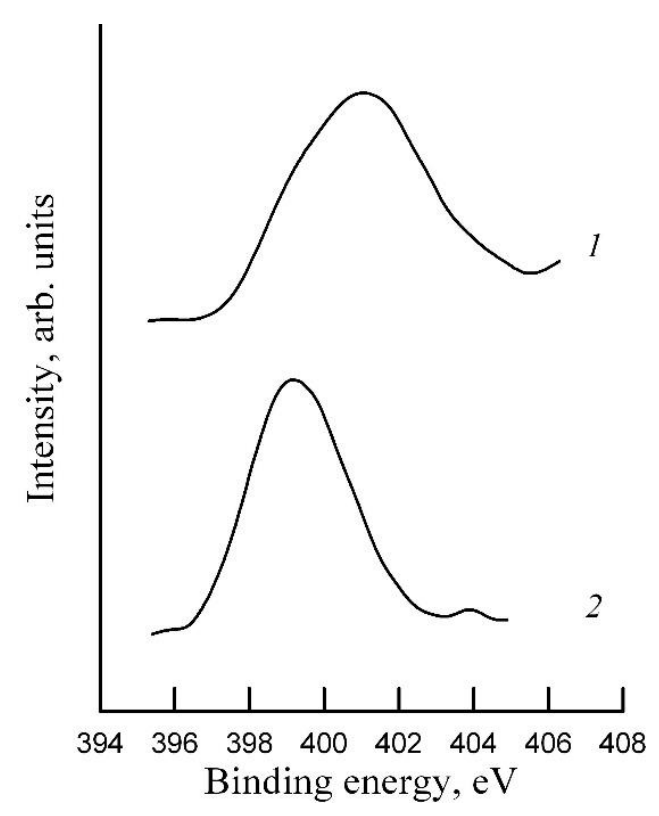

Figure 2. The XPS N1s-spectra of: (1) the nitrated oil of Steel 3 surface without heating; (2) the nitrated oil on Steel 3 surface at heating.

The investigation of the protective properties of the studied compositions was carried out according to method 3, GOST 9.054-75. The corrosive medium was an aqueous solution of $30 \mathrm{mg} / \mathrm{L} \mathrm{NaCl}+70 \mathrm{mg} / \mathrm{L} \mathrm{Na}_{2} \mathrm{SO}_{4}$ (an imitation of condensate at atmospheric corrosion). The samples from Steel 3 were dipped into the above solution at room temperature. The reference sample was cleaned, degreased and weighed in its initial state. The samples were coated with protective layers by dipping into the following protective compositions:

- oil I-20

- oil I-20+10 g/L of oil K-17

- oil I-20+20 g/L of oil K-17

(Note: oil K-17, GOST 10877-76)

- oil I-20+10 g/L of nitrated oil

- oil I-20+20 g/L of nitrated oil

The duration of tests was 3 days.

At the end of testing the samples were taken out from the corrosive medium and washed; corrosion products were removed by soft rags; after that the samples were dried and weighed. The calculation of the corrosion rate was carried out $\left(\mathrm{V}_{0}\right.$-without coating, $\mathrm{V}_{\text {coat }}-$ with protective coating), $\mathrm{V} \mathrm{g} / \mathrm{m}^{2} \mathrm{~h}$.

The degree of protection, $\mathrm{Z}$, was calculated:

$$
Z=\frac{V_{0}-V_{\text {coat }}}{V_{0}} \cdot 100
$$

The results are given in Table 1 . 
Table 1. The corrosion rate of the steel samples with the coatings under study.

\begin{tabular}{ccc}
\hline Additive concentration, $\mathbf{g} / \mathbf{L}$ & Corrosion rate, $\mathbf{g} / \mathbf{m}^{\mathbf{2}} \mathbf{h}$ & $\boldsymbol{Z}, \boldsymbol{\%}$ \\
\hline Background & 0.263 & - \\
Industrial oil (I-20) & 0.245 & 6 \\
Without additives & 0.163 & 38 \\
I-20+10 g/L oil K-17 & 0.125 & 52 \\
I-20+20 g/L oil K-17 & 0.093 & 65 \\
I-20+10 g/L nitrated oil & 0.053 & 80 \\
I-20+20 g/L nitrated oil & & \\
\hline
\end{tabular}

The results in the above table show that nitrated oil is significantly more effective than oil K-17 as a corrosion preventive.

The method of thermochemical activation could not be used in the described weightchanged method for corrosion measurement since the formed chemisorbed protective layer increased the mass of a sample, and after testing it was practically impossible to remove the protective layer, containing an inhibitor and corrosion products, for calculating the loss of the sample mass according to this method.

In this connection, we used the rapid method for the evaluation of the rate of sample corrosion with the help of a corrosion thickness gauge "Monicor". Specially prepared samples from Steel 3 were used for making detectors of corrosion which were dipped into the above-mentioned corrosive medium. The measurement showed that approximately in 2 hours the rate of the samples corrosion became almost constant for all variants of measurements. Therefore, this duration of testing was accepted.

The results of testing with the use of "Monicor" are certain relative rates of corrosion. Taking into account the difficulties of the determination of the device constant for our purposes, the rate of corrosion in the background solution was taken equal to 100 .

The samples for testing were prepared by dipping into the inhibitor solutions in industrial oil I-20. After that some samples underwent thermochemical treatment, i.e. for 20 min they were heated in a muffle furnace in the air at $50,100,200$ and $250^{\circ} \mathrm{C}$. As it has already been noted, after cooling the samples were studied for determining the corrosion rate using "Monicor".

The testing results are shown in Table 2.

The samples without protective coating were heated only to 50 and $100^{\circ} \mathrm{C}$, since at higher temperatures an oxide macrolayer of grey color (scale) began to form.

Thus, the data on the effectiveness of the compositions obtained in the studies with the use of the corrosion thickness gauge "Monicor" are close to those obtained by the weight methods (without thermochemical activation). Thermochemical activation considerably increases the effectiveness of the action of adsorption layers. 
Table 2. The calculation of the relative rate of corrosion with the use of the corrosion thickness gauge "Monicor".

\begin{tabular}{|c|c|c|c|c|c|}
\hline \multirow{3}{*}{ Additive concentration, $\mathrm{g} / \mathrm{L}$} & \multicolumn{5}{|c|}{ Relative rate of corrosion } \\
\hline & \multicolumn{5}{|c|}{ Thermochemical activation, ${ }^{\circ} \mathrm{C}$} \\
\hline & $\begin{array}{c}\text { Room } \\
\text { temperature }\end{array}$ & $50^{\circ} \mathrm{C}$ & $100^{\circ} \mathrm{C}$ & $200^{\circ} \mathrm{C}$ & $250^{\circ} \mathrm{C}$ \\
\hline background & 100 & 92 & - & - & - \\
\hline $\begin{array}{l}\text { Industrial oil (I-20) without } \\
\text { additives }\end{array}$ & 91 & 90 & 88 & 85 & 80 \\
\hline $\mathrm{I}-20+10 \mathrm{~g} / \mathrm{L}$ oil $\mathrm{K}-17$ & 35 & 32 & 30 & 28 & 28 \\
\hline $\mathrm{I}-20+20 \mathrm{~g} / \mathrm{L}$ oil K-17 & 30 & 28 & 26 & 24 & 24 \\
\hline $\mathrm{I}-20+10 \mathrm{~g} / \mathrm{L}$ nitrated oil & 18 & 16 & 5 & 6 & 6 \\
\hline $\mathrm{I}-20+20 \mathrm{~g} / \mathrm{L}$ nitrated oil & 12 & 9 & 4 & 3 & 3 \\
\hline
\end{tabular}

\section{Conclusion}

The XPS spectra of adsorption layers of nitrated oil and reference layers on Steel 3 surface have been obtained.

The regularities of the change of the chemical bond of the surface layers of Steel 3 and adsorption layers of nitrated oil have been established; the nature of the interatomic interaction of their atoms has been studied. The temperature conditions for the formation of the protective layers and the limits of the stability of the formed protective layers have been established. It is shown that the formation of a strong protective layer at the adsorption of nitrated oil takes place due to the formation of strong chemical bonds (donor-acceptor) between iron atoms and nitrogen atoms.

The corrosion tests show that nitrated oil I-20 decreases the rate of sample corrosion by almost a factor of 3. Thermochemical activation of such layer increases the protection functions even more. One can think that such treatment of an adsorption layer at solidification decreases its defects. Obviously, in this case the adsorption centers are nitrogen and oxygen atoms ensuring an effective adsorption protective layer.

The results obtained can be used for increasing the effectiveness of the use of known inhibitors.

\section{Acknowledgments}

The work was carried out as a part of the state assignment (state registration number AAAAA17117022250040-0). This study was performed using the equipment of the Shared Use Centre "The Centre of Physical and Physicochemical Methods of Analysis and Study of the Properties and Surface Characteristics of Nanostructures, Materials, and Products" of the Institution of Science "Udmurt Federal Research Centre of the Ural Branch of the Russian 
Academy of Sciences" and supported by the Ministry of Education and Science in the framework of the Federal Target Program "Research and Development in the Priority Directions of the Development of the Russian Science and Technology Complex for 20142020" (The unique identifier of the project is RFMEFI62119X0035).

\section{References}

1. N. Perez, Electrochemistry and Corrosion Science: Second Edition, Springer International Publishing, 2016, 455. doi: $\underline{\text { 10.1007/978-3-319-24847-9 }}$

2. R. Javaherdashti, How corrosion affects industry and life, Anti-Corros. Methods Mater., 2000, 47, no. 1, 30-34. doi: 10.1108/00035590010310003

3. G.H. Koch, M.P. Brongers, N.G. Thompson, Y.P. Virmani and J.H. Payer, Corrosion cost and preventive strategies in the United States, A supplement to Mat. Perf., 2002, 12. http://impact.nace.org/documents/ccsupp.pdf

4. S.E. Krein and Yu.N. Shekhter, Nitrated oils (production and usage), Moscow, Khimiya, 1967, 180 (in Russian). https://search.rsl.ru/ru/record/01006248851

5. Yu.N. Shekhter, V.M. Shkol'nikov, T.I. Bogdanova and V.D. Milovanov, Working preservation lubricants, Moscow, Khimiya, 1979, 256, (in Russian). https://search.rsl.ru/ru/record/01007810081

6. T.I. Bogdanova and Yu.N. Shekhter, Ingibirovannye neftyanye sostavy dlya zashchity ot korrozii (Inhibited oil compositions for corrosion protection), Moscow, Khimiya, 1984, 247 (in Russian). https://search.rsl.ru/ru/record/01001185397

7. M.K. Levitin, Yu.N. Shekhter, S.E. Krein, K.I. Bessmertnyi, A.V. Vilenkin, V.I. Goryacheva, A.L. Dol'berg, V.P. Kalashnikov, R.S. Lyakhovich, I.N. Rozvadovskaya, A.A. Romanovskaya, L.D. Khoroshilova and M.I. Sheremet, $A$ method to prepare a corrosion inhibitor for lubricating oils, 1964, SU 162616 A1, USSR (in Russian). https://yandex.ru/patents/doc/SU162616A1_19640508

8. O.A. Goncharova, A.Yu. Luchkin, Yu.I. Kuznetsov, N.N. Andreev, N.P. Andreeva and S.S. Vesely, Octadecylamine, 1,2,3-benzotriazole and a mixture thereof as chamber inhibitors of steel corrosion, Int. J. Corros. Scale Inhib., 2018, 7, no. 2, 203-212. doi: $\underline{10.17675 / 2305-6894-2018-7-2-7}$

9. N.A. Gladkikh, M.A. Maleeva, L.B. Maksaeva, M.A. Petrunin, A.A. Rybkina, T.A. Yurasova, A.I. Marshakov and R.Kh. Zalavutdinov, Localized dissolution of carbon steel used for pipelines under constant cathodic polarization conditions. Initial stages of defect formation, Int. J. Corros. Scale Inhib., 2018, 7, no. 4, 683-696. doi: 10.17675/2305-6894-2018-7-4-14

10. O.Yu. Grafov, L.P. Kazansky, S.V. Dubinskaya and Yu.I. Kuznetsov, Adsorption of depocolin and inhibition of copper dissolution in aqueous solutions, Int. J. Corros. Scale Inhib., 2019, 8, no. 3, 549-559. doi: $\underline{\text { 10.17675/2305-6894-2019-8-3-6 }}$ 
11. Ya.G. Avdeev, D.S. Kuznetsov, M.V. Tyurina and M.A. Chekulaev, Protection of nickel-chromium steel in sulfuric acid solution by a substituted triazole, Int. J. Corros. Scale Inhib., 2015, 4, no. 2, 146-161. doi: 10.17675/2305-6894-2015-4-1-146-161

12. I.A. Arkhipushkin, Yu.E. Pronin, S.S. Vesely and L.P. Kazansky, Electrochemical and XPS study of 2-mercaptobenzothiazole nanolayers on zinc and copper surface, Int. J. Corros. Scale Inhib., 2014, 3, no. 2, 78-88. doi: 10.17675/2305-6894-2014-3-2-078-088

13. V.A. Trapeznikov, I.N. Shabanova, A.V. Kholzakov and A.G. Ponomaryov, Studies of transition metal melts by X-ray electron magnetic spectrometer, J. Electron Spectrosc. Relat. Phenom., 2004, 137-140, 383-385. doi: 10.1016/j.elspec.2004.02.115

14. I.N. Shabanova, R.A. Nurullina, V.A. Trapeznikov and J.G. Manakov, Electronic magnet spectrometer, RU Patent 2338295 C1, 2008, IPC H01J49/48 (in Russian). https://patenton.ru/patent/RU2338295C1/en 